\title{
The Application of Herzberg's Two-Factor Theory in Management -- Taking Huawei and Lenovo as Examples
}

\section{Jia Ju}

Henan University, Kaifeng 475001, Henan Province, China

\begin{abstract}
The report mainly shows the methods of Huawei and Lenovo's managers to manage the organizations to achieve goals. First, it gives the overviews of Huawei and Lenovo which are two of the largest communication devices manufacturers, provides a departmental structure. Second, it simply explains the meaning of management and management personnel in this report. Then, it analyzes Two-Factor Theory. It provides their successful cases with using Two-Factor Theory. Finally, it provides a conclusion of similarities and differences between them and offers recommendations.
\end{abstract}

Key words: Huawei; Lenovo; Organization; Company

Publication date: April, 2021; Publication online: 30 April, 2021

*Corresponding author: Jia Ju, jujia007@126.com

\section{Introduction}

\subsection{Purpose of the report}

The purpose of this report is to find ways that the managers who come from Huawei and Lenovo can effectively manage workplace relationships and produce a desired result. The report describes the methods of how to build standards of performance and strategies to achieve organization's goals, responsibilities of both managers and employees. Also, it describes the theory and usage of motivation in Huawei and Lenovo. Finally, it provides a conclusion of similarities and differences between two organizations, and it provides recommendations regarding best practice for organizations to operate better.

\subsection{Methodology}

The methodology of this report mainly uses secondary data, which come from websites, books and database.

\subsection{Overview of Huawei}

Huawei is a provider of information and communication technology (ICT) infrastructure and intelligent equipment. Huawei has its own suppliers all over the world. Its customers are mainly major electronic communication companies, schools, research institutes, etc. Huawei's vision is 'Building a Fully Connected, Intelligent World'. Huawei's mission is 'to focus on the challenges and pressures of customers' attention, provide competitive communication solutions and services, and continue to create the maximum value for customers'. The organization structure is showed in Figure $1^{[1]}$. 


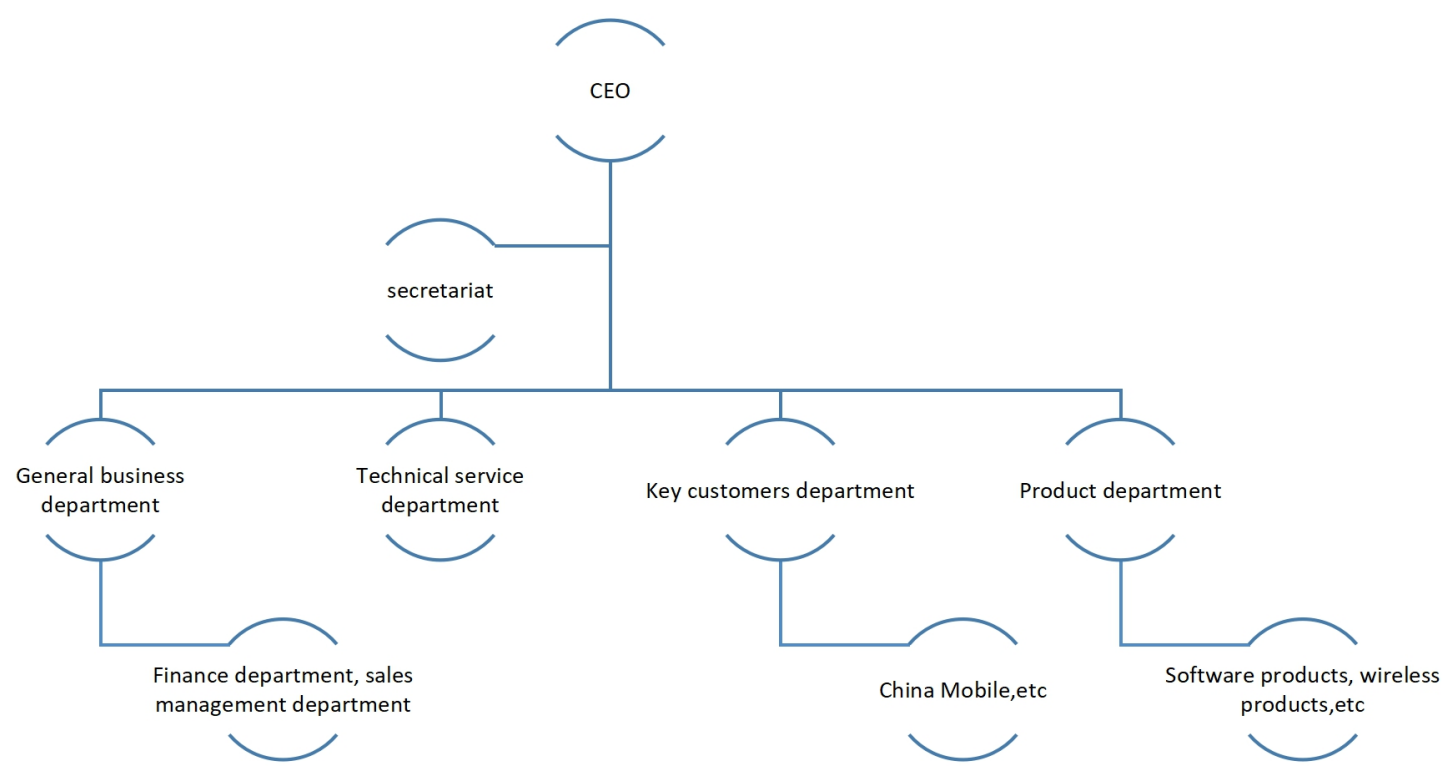

Figure 1. Organization structure of Huawei

\subsection{Overview of Lenovo}

Lenovo is a large IT company in China. Lenovo mainly produces computers, TVs, servers, and other products. Lenovo's vision is 'creating personal devices that more people are inspired to own, a culture where more people aspire to join and an enduring, trusted business that is well respected around the world'. Their mission is to 'become one of the world's greatest personal technology companies'. Lenovo's organizational structure has undergone many changes, and now it adopts the "aircraft carrier" organizational structure, the organization structure is showed in Figure $2^{[2]}$.

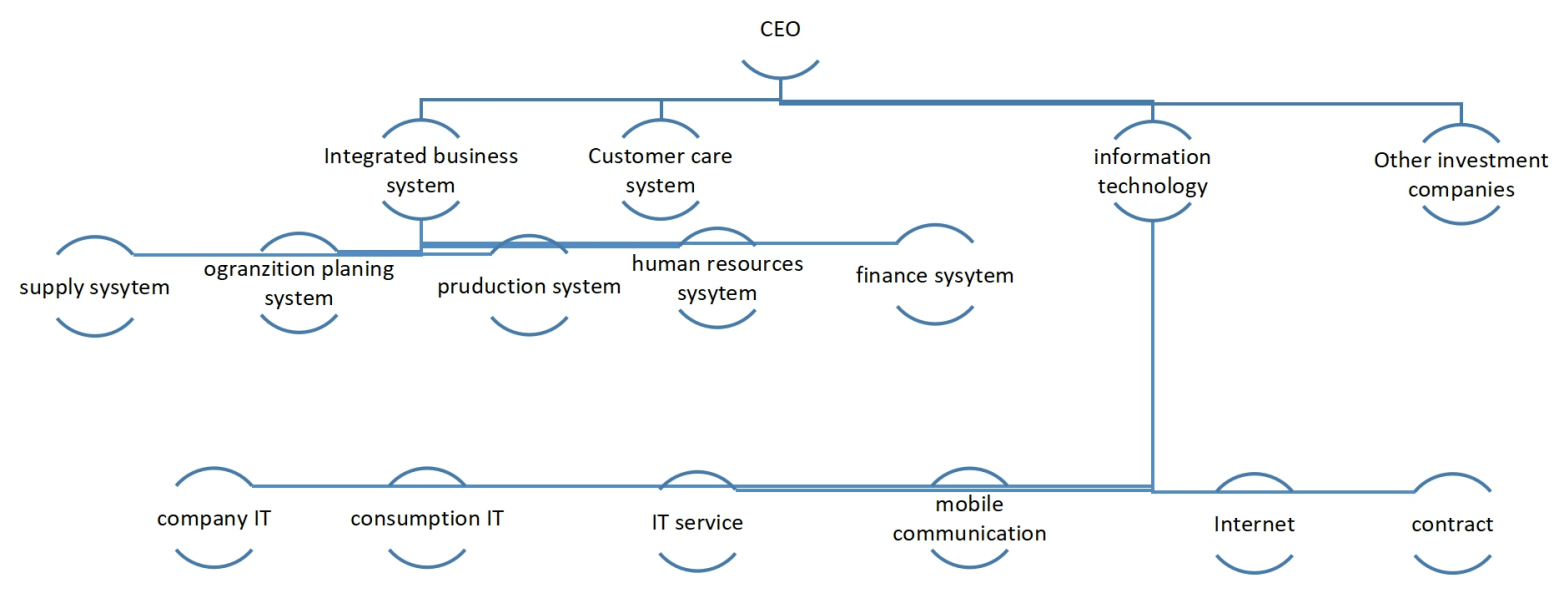

Figure 2. Organization structure of Lenovo 


\section{Findings \& analysis}

\subsection{What managers do?}

Managers need to optimize the management process, establish management systems and standards, use charts, performance appraisal and other management tools to complete the tasks and finally evaluate the matters and decisions of the enterprise. Furthermore, they should also carry out the four major functions of management which are planning, organizing, leading and controlling.

Organizations can take five ways to achieve organizational goals. They are stimulating the innovation of the organization, adhering to sustainable development. Then, it is crisis and risk management with improving the quality of work and life of employees and establishing a learning organization.

A successful manager needs have three key managerial skills, including technical skills, interpersonal skills and conceptual skills. Technical skills mean that the professional knowledge or skills in a specific field that employees need to skillfully and accurately complete the work. For frontline managers, technical skills are more important than others. Interpersonal skills involve the ability to communicate well with others, which can coordinate the relationship between the members, make the members get along well and make the team more cohesive. Then, conceptual skills refer to manager transform abstract, complex concepts or situations into concrete and enforceable states and use these capabilities to view the organization as a whole and understand the relationship of subunit.

\subsection{Management employee relationship -- What motivates?}

\subsubsection{Two-factor theory of motivation in detail}

Herzberg's two-factor theory points out the factors that affect employees' job dissatisfaction and satisfaction and divides these factors into Hygiene factors and motivator factors. Hygiene factors include company policy and management, salary and working conditions, etc. These are negative external factors about work, Hygiene factors will not bring long-term satisfaction. However, if the organization does not provide them with these factors, employees will be dissatisfied. In other words, Hygiene factors refer to those that can appease employees and reduce dissatisfaction. Motivator factors include recognition, achievement, and responsibility, etc. These factors are related to the employees' positive emotions towards the work content.
Motivator factors are related to the work content itself and can produce satisfaction, it generally reflects the psychological needs of employees and is an intrinsic factor. It inspires employees to pursue outstanding performance.

According to Herzberg's theory, satisfaction and dissatisfaction affected by these two kinds of factors can exist at the same time. That is means that Hygiene factors inhibit employee dissatisfaction, while motivator factors help improve satisfaction. A person can feel satisfaction and dissatisfaction at the same time. Therefore, Hygiene factors and motivator factors do not affect each other. For example, eliminating employee does not necessarily mean that employees will be satisfied and vice versa. Additionally, in an organization, if leaders focus on eliminating unsatisfactory work factors, it may bring peace, but not necessarily improve performance.

Herzberg's two factor theory also has limitations. Firstly, when things go well, people tend to see what they enjoy to work for. However, when things get worse, they tend to blame external factors. This situation will affect Herzberg's experimental results, thus reducing the credibility of the theory. Second, the two-factor theory holds that employees' job satisfaction will affect productivity. However, Herzberg does not explain this relationship, and there are other external factors that affect productivity.

Although the theory is not perfect, the two-factor theory can still provide managers with many ideas to motivate employees. In the application of this theory, managers use two-stage process to motivate people. First, managers need to eliminate the dissatisfaction of employees. For example, ensure effective supervision, pay salaries honestly, and provide job security. Second, when dissatisfaction disappears, managers need to help them find a place of satisfaction. For example, providing development opportunities, recognizing people's contributions, and providing training.

\subsubsection{Huawei}

Huawei has established a complete salary system to reduce employee dissatisfaction and attract new staffs in terms of Hygiene factors. Huawei uses high salary to attract more talents to take office. It is reported that in 2011, the starting salary of Huawei's new students is 5000-6000 RMB for undergraduates, this set of basic wage standard is in the forefront in the same industry and even in the market ${ }^{[3]}$. Huawei's high salary raise will attract many excellent talents, and meet the most basic requirements of employees for work. 
Employees' dissatisfaction caused by high pressure work is reduced due to their higher salary than that of the same industry.

Huawei established of honor department, which have improved employee satisfaction from the perspective of motivators and retain high quality staffs. Huawei has set up an honor department to enhance employees' sense of honor. Huawei has set up an honor department to assess and evaluate the work of employees, reward each employee's hard work, and at the same time, the department has also set up various forms of rewards, such as honor, training, career development incentive ${ }^{[4]}$. This will improve employee job satisfaction and encourage employees to contribute their own strength to the development of the company.

Refer to the responsibilities of employees, each employee of Huawei completes his team role, the manager also has a more active contact with employees through incentive system such as equity incentive, Huawei excellent job design promotes good performance. For example, in Huawei's equity incentive policy, the organization requires the types and quantities of shares that employees can subscribe for. Huawei will evaluate the roles of employees in the team. When the team is established, Huawei makes a clear roles' task for the team, then evaluate the performance of each role according to the results of the task ${ }^{[5]}$. Huawei's team role defines the responsibilities of employees, and Huawei's equity incentive policy encourages employees to actively perform their duties. Huawei well job design enables employees to work efficiently and pay more attention to organizational performance.

\subsubsection{Levono}

In terms of Hygiene factors, Lenovo provides good working environment for employees and attracts more people to work. Lenovo has a company canteen which provides free lunch for employees and dormitories for new employees who come from other places. It has developed rapidly and realized a high degree of office automation Meanwhile, it also provides home computers for employees who work at home, and sends them to employees' homes one by one ${ }^{[6]}$. Lenovo's working environment will attract a lot of graduates, and talents from other places to work in the enterprise, which can meet the basic needs of employees to do life, thus reducing job dissatisfaction.

In terms of motivator factors, Lenovo implements equity incentive policies, which improves employees' sense of responsibility and satisfaction, and enables employees to stay in the company for a long time to create profits for Lenovo. Lenovo provides internal stock for the company's managers, employees can purchase according to their own wishes, and sell it to Lenovo at the market price when they leave. Lenovo also provides a variety of forms of internal stock purchase, in addition to using cash on hand, employees can also subscription with bonus or interest free loan from the company ${ }^{[7]}$. Lenovo's equity incentive enables employees to pay more attention to the performance and long-term development of the enterprise, and enables employees to stay in the company for a long and feel satisfied with the results while working hard.

Refer to the team roles, Lenovo has more incentives for highly skilled employees, its strict and clear management system helps the organization well designed the job and improve performance. Lenovo defines the supervision system of managers and the supervision responsibility of employees in the employee manual ${ }^{[7]}$. These systems complement the lack of supervisory roles in Lenovo's team, at the same time, standardized system reduces the dissatisfaction of employees. Lenovo's well job design ensures the organization's centralized management of its employees and makes them work towards the organization's goals which can get good performance.

\section{Conclusion and recommendations}

In conclusion, the report explains Two-Factor Theory of Motivation of Huawei and Lenovo cases.

There are many similarities between them. To encourage employees to work hard, both leaders established reasonable compensation system and allocated shares. They emphasized efficiency and teamwork, so Huawei and Lenovo had made great achievements in Chinese market. Meanwhile, they had realized the importance of technology and innovation and recruited a group of capable employees for the organizations.

Also, there are many differences. Ren used military-style management, so Huawei attaches more importance to efficiency, rules and regulations. However, the team model in Huawei is more perfect than Lenovo's team model, and its members have more distinct roles. Lenovo's leaders delegate power to their subordinates and pay more attention to employees which are different from Huawei's centralized management.

To cope with the increasingly fierce competition of IT industry, Huawei should strengthen the research, develop core technologies and provide employees with benefits to 
increase their satisfaction. After Liu's retirement, Lenovo should focus on the improvement of its leadership model and improve its incentive system continuously.

\section{References}

[1] Huawei. (n.d). Vision, Huawei. [Online]. Available at: https://www.huawei.com/en/fully-connected-intelligent -world. (Accessed: 2 February 2021)

[2] Lenovo (n.d). About Lenovo. Lenovo. [Online]. Available at:

https://www.lenovo.com/us/en/about/whoweare.

(Accessed: 2 February 2021)

[3] Zhang X. Research and Enlightenment of salary management in Huawei[J]. Shanghai Foreign Studies University,2012, 3:37-46.

[4] Zhu ZL, Qiao WL, Niu J. On the incentive mechanism of Huawei[J]. Economic Outlook the Bohai Sea, 2018. $5: 127$.

[5] Yuan MQ. Huawei's incentive mechanism and inspiration[J]. China Collective Economy, 2018,30: 51-52.

[6] Zhu Y. The role of incentive mechanism in company management -- Taking Lenovo Group as an example[J]. Chinese Market, 2020,04:92-93.

[7] Wang YR. Comparison of incentive mechanism of Huawei Lenovo[J]. New Economy, 2016,24:36-37. 